\title{
IMPROVEMENT OF A POWER GENERATION TURBINE DISC PROCESS USING A FINITE ELEMENT MODEL INCORPORATING METALLURGICAL PARAMETERS
}

\author{
J. Huez, J-L. Noyes, F. Pouey and J-F. Uginet \\ FORTECH \\ BP 173 - 09102 PAMIERS cedex - FRANCE
}

\begin{abstract}
$\underline{\text { Abstract }}$
In die forging of superalloys, the conditions of strain and of the subsequent heat cycle have a significant influence on the structure and properties of the final product. This is why the determination and modelling of grain size development during and after deformation is of primary interest.

In this paper, using simulation and experimental tests, we investigate the thermal way of two different critical locations of an industrial part with a view to enhancing the knowledge of the forging thermal range and therefore to optimize the process.

It appears that by this method, we are able to adapt the thermomechanical path to the geometrical form of the part. Today, the finite element model is not only used to correctly predict the material flow occurring in the part, but as this study will illustrate, numerical simulation has become an essential tool for process optimization and improvement of microstructure.
\end{abstract}




\section{$\underline{\text { Introduction }}$}

706 alloy is now a well established alloy, used for large land turbine parts in whose service conditions require high temperatures. A major factor in the choice of this alloy was the reduced amount of niobium allowing material availability in the form of large ingots. Even with internal defects that remain undetected by ultrasonic testing, its static and dynamic properties, associated with reasonable impact toughness and fatigue cracks growth rate allow service safety.

In this field, FORTECH, as a major supplier of these parts, has always tried to improve its process capability. 3D and 2D finite element model (FEM) software has become an essential tool for process optimization and amelioration. Today, reasonably accurate modelling of the microstructure is available for such an alloy which also offers development possibilities.

FORTECH, a few years ago, having investigated its thermomechanical behaviour, determined semi-empirical equations describing the microstructural evolution of the Inconel 706 alloy. Introduced in the Forge2 $\mathbb{B}_{\text {software[4]. }}$ the parameters and analytical decription of the evolution of the 706 alloy microstructure, has allowed us to predict grain size and the recrystallized grain fraction.

In this paper, some improvements in the process will be presented.

With the aim of optimizing the key parameters, and therefore enhancing the process capability, we will study the differences in thermal path in parts of different mass. These variations could affect the microstructure even for minor changes in initial temperature.

\section{Material}

The chemical composition of alloy 706 used in this investigation is given in Table $\mathrm{I}$.

The microstructure of alloy 706 is governed by the fcc lattice of the $\gamma$ matrix associated with characteristic precipitates such as the aluminum rich fcc $\gamma^{\prime}$ phase. The presence of this precipitate is the essential strengthening mechanism in this alloy. $\gamma$ ' will transform to a stable hexagonal $\eta$ phase during elevated temperature exposure. The solvus temperature of the $\eta$ phase in the present material is $\sim 954^{\circ} \mathrm{C}$.

TABLE I Chemistry of alloy 706 used. Weight Percentage.

\begin{tabular}{cccccccccc}
$\mathrm{Ni}$ & $\mathrm{Fe}$ & $\mathrm{Cr}$ & $\mathrm{Nb}$ & $\mathrm{Ti}$ & $\mathrm{Al}$ & $\mathrm{Mn}$ & $\mathrm{C}$ & $\mathrm{Si}$ & $\mathrm{S}$ \\
\hline 40.55 & 38.74 & 15.83 & 2.84 & 1.71 & .18 & .14 & .034 & .03 & .006
\end{tabular}

The main steps of the processing route of alloy 706 are summarized hereafter [1]:

The alloy 706 is triple melted: the primary melting is a Vacuum Induction Melting (VIM), followed by an Electro Slag Remelting (ESR), and a final Vacuum Arc Remelting (VAR).

An upsetting and drawing of the ingot is carried out well above the recrystallization temperature before the close die forging. Generating a uniform level of strain throughout the workpiece is key to producing a uniform microstructure .

Grain size of ASTM 0-1 is obtained after billetizing (see figure 1).

Figure 1 : billet microstructure

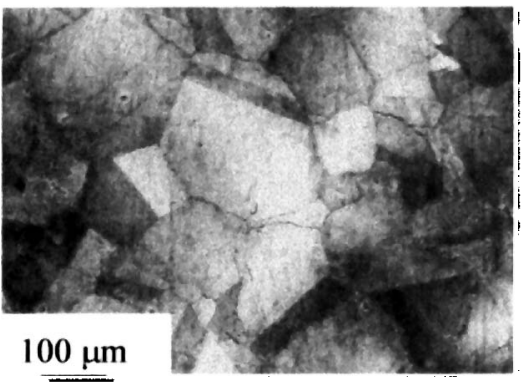

\section{Modelling}

By the use of the finite element method the prediction of mechanical, thermal and structural conditions is possible but material data has first to be well defined.

Knowledge of both the thermomechanical behaviour and thermophysical properties of the material as well as that of the kinetic tools is essential to give an accurate description of the deformation process. Also, from experimental data and simulation, we obtained the microstructure, and the thermal and strain field in the material. Then, by an Avrami-Sellars analysis we are able to predict the development of microstructure.

The model detailed elsewhere [2-3] is summarized here briefly (figure 2). 


\section{Effective Coulomb friction coefficient (Coulomb law)}

\section{Calorific capacity}

Thermal conductivity

Emissivity

Global transfer coefficient : heat transfer coefficient between die and workpiece and exterior area interface Losses by radiation and convection are taken into account as are conduction effects and adiabatic heating produced during deformation.

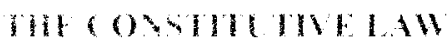

The constitutive law used is the NortonHoff model, expressed as follow:

$$
\sigma=\sqrt{3}^{m+1} K(T) \stackrel{\bullet}{\varepsilon}^{m}\left(\varepsilon_{0}+\varepsilon\right)^{n}
$$

with $\sigma$ the stress flow

$\mathrm{K}(\mathrm{T})=\mathrm{K}_{0} \exp (\mathrm{Q} / \mathrm{RT})$ the strength constant of the material,

$\varepsilon$ the strain

$\varepsilon_{0}$ the strain hardening regularization term

$\varepsilon$ the strain rate

$\mathrm{n}$ the strain hardening coefficient

$m$ the strain rate hardening coefficient

\section{HOROSTRICWRE EVOLUTIONS}

:

MODELLING

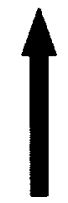

THE KINEll6 rools

For an accurate calculation, we take into account a driving velocity application, simulating a hydraulic press.

The expression of the recrystallized fraction and of the grain size after static recrystallization are :

$$
X=1-\exp \left[\ln (0.5) \cdot\left(\frac{t}{t_{0.5}}\right)^{k}\right]
$$

where $X$ is the recrystallized fraction, $t$ the time, $t_{0.5}$ the necessary time to have $50 \%$ of the structure recrystallized and $\mathrm{k}$ the Avrami exponent.

And

$$
t_{0.5}=\alpha \varepsilon^{a} Z^{h} D_{0}^{c} \cdot \exp \left(\frac{Q_{r e x}}{R T_{r e x}}\right)
$$

$$
Z=\stackrel{\varepsilon}{\varepsilon} \cdot \exp \left(\frac{Q_{d e f}}{R T_{d e f}}\right) \quad d_{r e x}=\beta \varepsilon^{n} D_{0}^{m} Z^{\prime}
$$

with $Z$ the Zener-Hollomon parameter, $R$ the universal gas constant, $D_{0}$ and $d_{r e x}$ respectively the initial and the final recrystallized grain size (in $\mathrm{mm}$ ), $Q_{\text {def }}$ the activation energy for hot deformation, $Q_{\mathrm{rex}}$ the activation energy for static recrystallization, $T_{\text {def }}$ the temperature of deformation and $T_{\text {rex }}$, the temperature of subsequent annealing. $\alpha, \beta, \mathrm{a}, \mathrm{b}, \mathrm{c}, \mathrm{n}, \mathrm{m}$, and $\mathrm{l}$ are constant.

The experimental results allow finding the parameters of the expression

$$
A^{n}=A_{0}^{n}+B \cdot \exp \left(\frac{Q_{g g}}{R T}\right) \cdot t
$$

A the mean area of the grain at $\mathrm{t}, \mathrm{A}_{0}$ the mean area of the initial grain (in $\mathrm{mm}^{2}$ ),

$\mathrm{Q}_{\mathrm{gg}}$ the activation energy for grain growth,

B a constant.

The analytical description of the evolution of the microstructure is introduced in the Forge $2 \mathbb{B}$ software. 
Industrial application

\section{Definition of task}

The model has been used for the industrial production of gas turbine discs.

The first aim of this task is to adapt the temperature and the re-heating time to the geometrical form of the gas turbine disc in order to control the thermomechanical behaviour and therefore reaching the target microstructure. The second, is to find a common temperature range for various discs, optimizing the furnace loads.

The dimensions of the billet vary from 0.7 to $0.9 \mathrm{~m}$ concerning the diameter, with a length to diameter ratio of approximately 2 . Massivity varies from one dise to another making it necessary to reach a better understanding of the production parameters in function of the disc shape. For example, it would appear that sometimes, in the center of the thicker disc $(9 \mathrm{~F})$, a grain growth is observed which does not occur in that of the thinner one (7F) under similar process conditions (see figure 3 ).

Through this study we will try to determine the temperature range within the part throughout the forming process, allowing it to reach the target microstructure everywhere in any shape of disc.

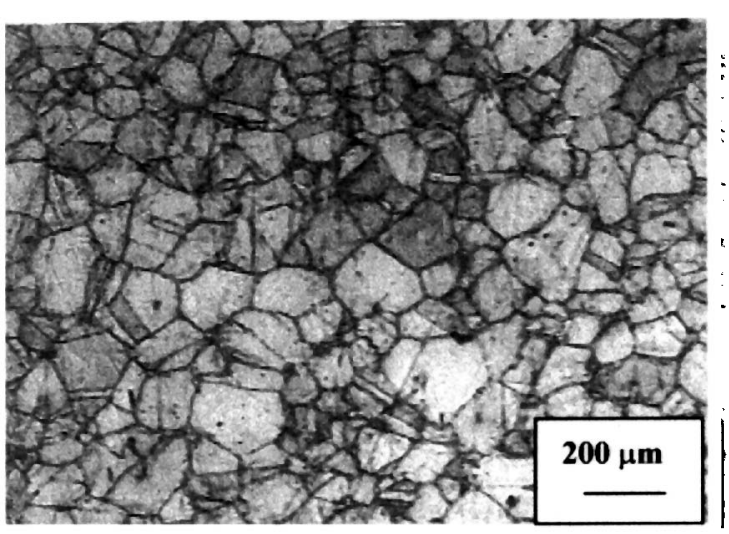

a)

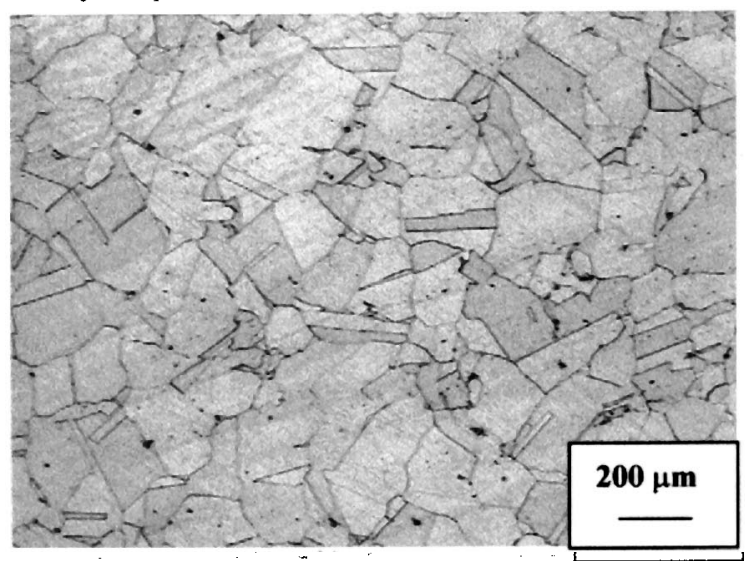

b)

Figure 3 : Microstructure in the center of the finished part for an initial temperature of $T_{0}$. a) $7 F$, b) $9 F$.

The simulation of the forming process of $9 \mathrm{~F}$ and of $7 \mathrm{~F}$ discs has been carried out from real production data (transfer time, time spent in and out of the furnace, press effort, strain rate ...) at an initial temperature of $\mathrm{T}_{0}$.

The forging process, described figure 4 , consists of 2 forming steps :

1) an upsetting followed by punching and then another upsetting.

2) punching (on the other face of the part) followed by close die forging .

From these simulations, we are able to correlate a precise microstructure evolution of a thermomechanical path.

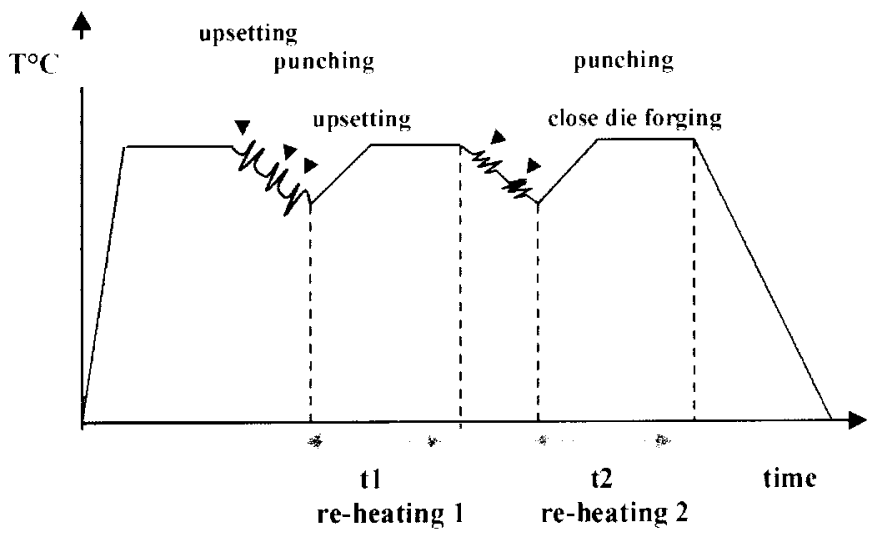

Figure 4 : Scheme of the industrial process studied and simulated 


\section{$\underline{\text { Simulation results }}$}

The two simulations have been done supposing an initial grain size of 1 ASTM.

From these simulations, it would appear that during the first heat of the thicker disc (9F), just before the second punching, a high temperature associated with an elevated strain in the center of the part allows the growth of the previous recrystallized grain to an ASTM of 2 (see figure 5).
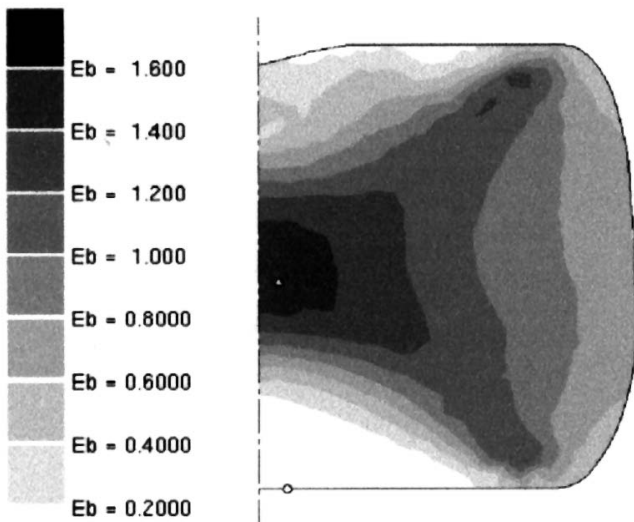

a)

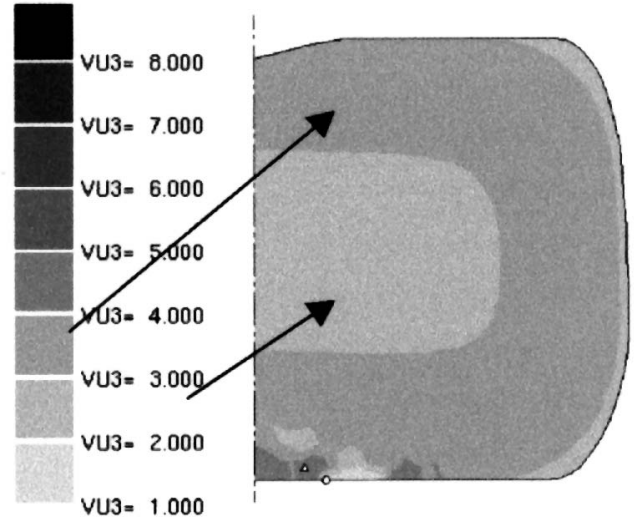

b)

Figure $5:$ Strain (a) and grain size (b, in ASTM indice) maps at the end of the first heat of the $9 \mathrm{~F}$ forming process at an initial temperature of $T_{0}$.

The microstructure on the surface does not have sufficient energy to enable growth and therefore, the grains are finer. The coarser central grains remain unchanged by the thermomechanical path of the second heat, as found on the finished part.

The same forming process of a thinner disc (7F) gives an homogeneous final microstructure (figure 6).

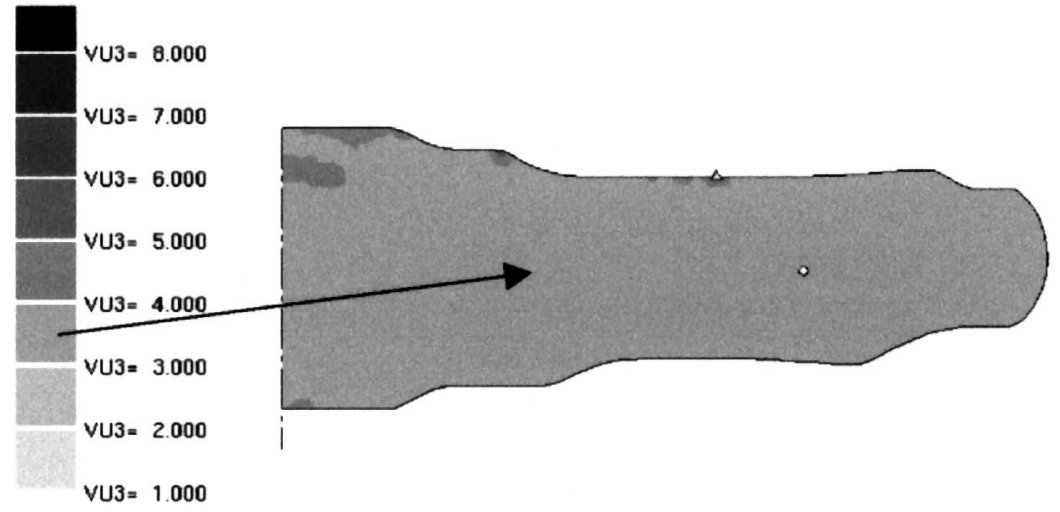

Figure $6:$ Grain size map obtained after the second heat of the $7 \mathrm{~F}$ disc at an initial temperature of $\mathrm{T}_{0}$.

A continuous and precise observation of the temperature at the center of each part, gives us information about the microstructure evolution and the important parameters to control.

Figure 7 indicates the temperature in function of time in the center and on the surface of the two discs.

\section{Center temperature}

During the first heat : in the first part of the process, immediately after the deformation and the loading into the furnace, we can observe that the thermomechanical path differs from surface and center on both discs.

In the center, the adiabatic heating plus re-heating gives a higher range of temperature, particularly for large $9 \mathrm{~F}$ parts $\left[\mathrm{T}_{0}+30{ }^{\circ} \mathrm{C}, \mathrm{T}_{0}{ }^{\circ} \mathrm{C}\right]$ compared to that of the smaller $7 \mathrm{~F}$ parts. 
During the second part of the process, when the part regains its furnace temperature, important differences can be observed between the two discs. In the case of the large $9 \mathrm{~F}$, the temperature gradually decreases from $T_{0}$ to $T_{0}-20^{\circ} \mathrm{C}$ whereas in the case of the $7 \mathrm{~F}$ it increases from $\mathrm{T}_{0}-30$ to $\mathrm{T}_{0^{-}}-10^{\circ} \mathrm{C}$.

During the second heat, due to the change of geometrical form, the same thermal behaviour pattern is observed between the two discs: firstly, an adiabatic heating plus re-heating in a temperature range of $\mathrm{T}_{0}+20$ to $\mathrm{T}_{0}-50^{\circ} \mathrm{C}$ followed by a temperature increase to $\mathrm{T}_{0}-20^{\circ} \mathrm{C}$.

\section{Surface temperature}

Concerning the surface temperature throughout the process, both discs have a similar behaviour pattern : during the two heats a decrease of temperature until furnace loading, followed by an increase of temperature reaching an equilibrium at furnace temperature.

\section{Temperature ${ }^{\circ} \mathrm{C}$}

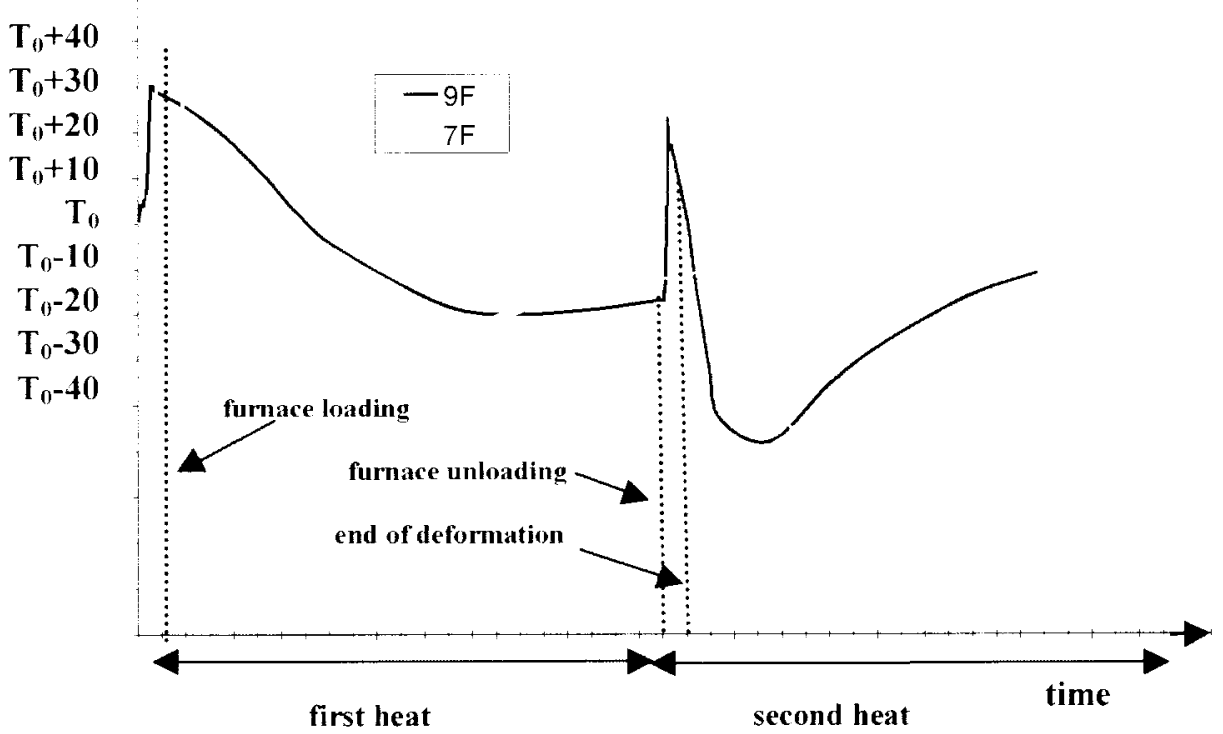

\section{Temperature ${ }^{\circ} \mathrm{C}$}

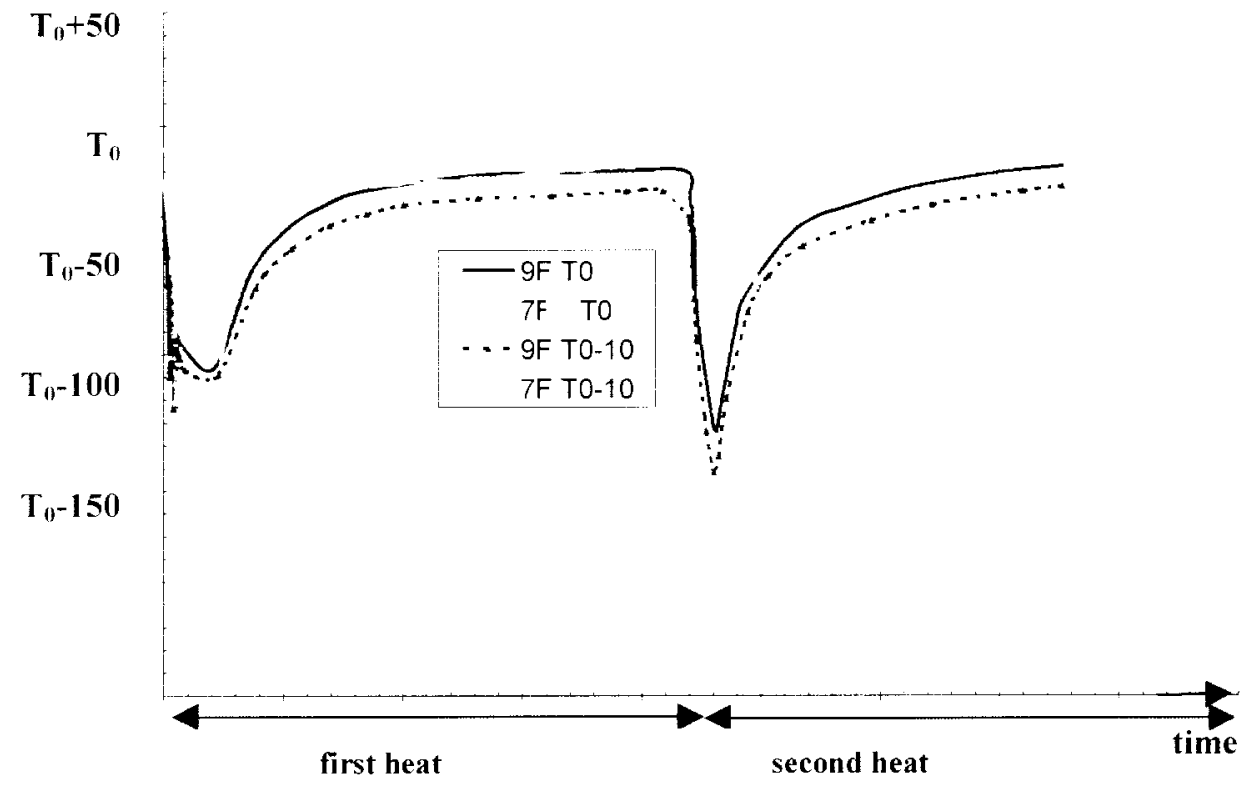

Figure 7 : Thermal cycles obtained from the simulation of the $9 \mathrm{~F}$ and of the $7 \mathrm{~F}$ from an initial temperature of $\mathrm{T}_{6}$. a) the center of the part (textual information applies to $9 \mathrm{~F}$ part)

b) $50 \mathrm{~mm}$ below the surface, in the bore area of the part 
A small decrease $\left(10^{\circ} \mathrm{C}\right)$ of initial temperature has been investigated. The simulation of the two forming processes have been made at this lower temperature: $T_{0}-10^{\circ} \mathrm{C}$. The results are presented in figure $7 \mathrm{~b}$ and figure 8 .

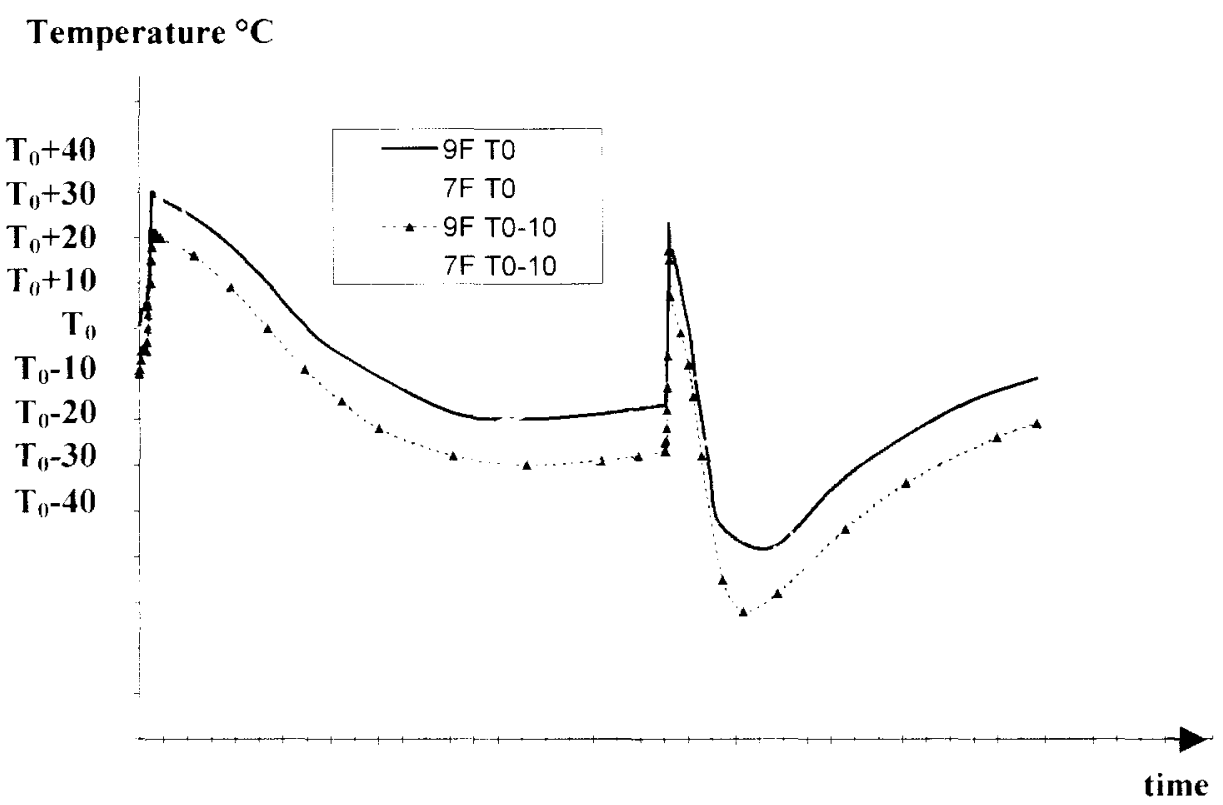

Figure 8 : Thermal cycles in the center of $9 \mathrm{~F}$ and $7 \mathrm{~F}$ discs, obtained from the simulation for an initial temperature of $\mathrm{T}_{0}$ and $\mathrm{T}_{0}-10^{\circ} \mathrm{C}$.

The curves have generally moved down to lower temperatures.

Concerning the first heat of the $9 \mathrm{~F}$, the decrease of $10^{\circ} \mathrm{C}$, has a great impact on the center of the part, reducing the time spent at temperature of above $\mathrm{T}_{0}-20^{\circ} \mathrm{C}$ by a factor of 2 .

This first approach shows that it is of primary importance to master the thermal path.

Our metallurgical knowledge of the 706 shows that above $T_{0}-20^{\circ} \mathrm{C}$ the evolution of grain size in function of the time may be important. This could explain the differences observed on the $7 \mathrm{~F}$ and $9 \mathrm{~F}$ discs at the central location.

We try to reproduce the thermomechanical way seen by the part on a test sample with cylinders of $40 \mathrm{~mm}$ in diameter and in length. The objective is to clearly demonstrate the effect of the thermomechanical path on the microstructure evolution, and also to experimentally verify that the grain growth observed in the center of the $9 \mathrm{~F}$ part at $\mathrm{T}_{0}^{\circ} \mathrm{C}$ is, in fact, due to the fisrt heat process.

\section{Experimental results}

We select two differents critical conditions corresponding to the center and surface of the $9 \mathrm{~F}$ disc.

Using simulation, we know how many upsettings the sample should have, to represent the same central and surface strain state as that of the real part. Following this upsetting, the sample is subjected to the same thermal cycle as that of the part (see figure 9).

A second modelling of the sample process has been carried out to obtain its microstructure in order to reinforce the accuracy of our model.

The test have been carried out for the first and second heat, at two temperatures $\left(T_{0}\right.$ and $\left.T_{0}-10^{\circ} \mathrm{C}\right)$ allowing us to experimentally access the intermediate microstructure of the part (between the two heats).

The final microstructure of each sample is observed and compared to those obtained on the part. Some results are presented in figure 10. 


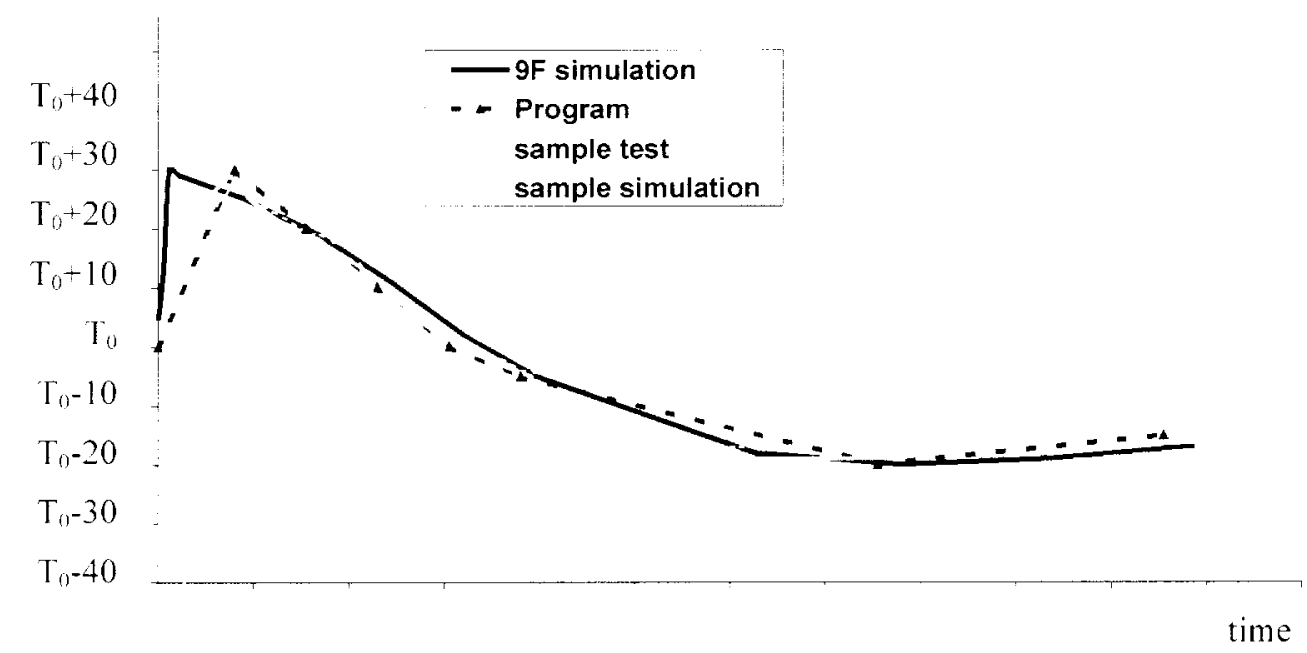

Figure 9 : Comparison of various thermal cycles used for this study. Example is given for the first heat of the $9 \mathrm{~F}$ dise in the central location.

«9F simulation » corresponds to the thermal cycle obtained from the simulation

«Program » corresponds to the thermal cycle programmed to do a sub scale test

« Sample test » corresponds to the temperature registered on the test sample instrumented with a thermocouple

"Sample simulation » corresponds to the thermal cycle obtained from the test sample simulation

\begin{tabular}{|l|c|c|c|c|}
\hline & Initial temperature $^{\circ} \mathbf{C}$ & Simulated grain size & Test sample grain size & Part grain size \\
\hline First heat & $\mathrm{T}_{0}$ & $2-3$ & $2-3$ & - \\
\hline First heat & $\mathrm{T}_{0}-10$ & $3-4$ & $3-4$ & - \\
\hline Second heat & $\mathrm{T}_{0}$ & $2-3$ & $2-3$ & $1-2$ \\
\hline Second heat & $\mathrm{T}_{0}-10$ & $4-5$ & $3-4$ & $3-4$ \\
\hline
\end{tabular}

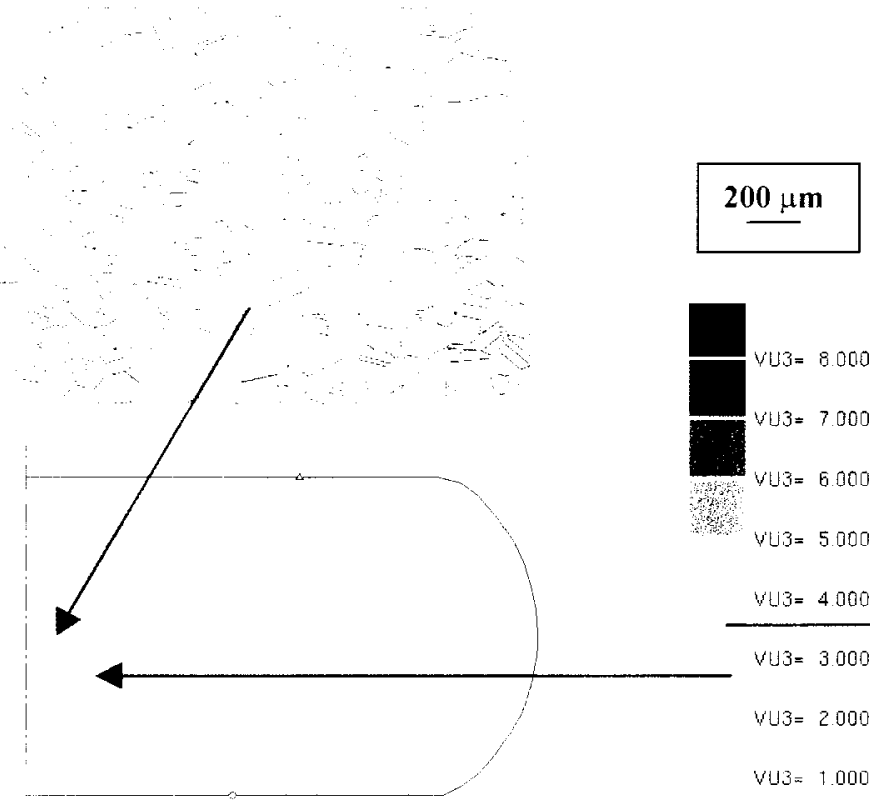

Microstructure and simulation at $T_{0}$ First heat

Microstructure and simulation at $\mathrm{T}_{0}-10^{\circ} \mathrm{C}$ First heat

Figure $10:$ Results on the test samples reproducing the central microstructure on a $9 \mathrm{~F}$ part. Grain size are given in ASTM indices. 
It appears that for a temperature of $\mathrm{T}_{0}$, the grain growth observed in the center of the part can also be observed in that of the sample, which is not the case for the surface conditions. Also, it is clear that the second heat is not responsible for this grain growth. In fact, the microstructure of the sample, which has been subjected to the fisrt heat thermal path, remains unchanged by the second heat.

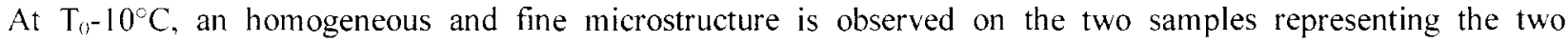
locations.

From these results, $\mathrm{T}_{0}-10^{\circ} \mathrm{C}$ seems to be the suitable temperature for a common process of both discs.

\section{Conclusion and perspectives}

From this complete study where we analysed:

- industrial microstructure observations on two dises,

- forming process simulation allowing to evaluate the final grain size distribution of the part

- test sample reproducing the two heats of the industrial process at a sub scale

- test sample simulation to reinforce the accuracy of the model,

it has been pointed out that a reduction of $10^{\circ} \mathrm{C}$ on the initial temperature, allows us to reach a common microstructure on two different dises and therefore to optimize the furnace loading and productivity.

Another advantage is the possibility to optimize industrially the process under the $65 \mathrm{KT}$ press. This can be achieved in different ways, by coupling various parts of different shapes in the same batch which allows flexibility, or, by reducing production time without affecting the metallurgical results. Each of these proposed solutions could be applied in order to obtain the most efficient process.

[I] D. Rayne, J.F. Uginet, "Fabrication of large components in 706 Alloy for gas turbine application ". $11^{\text {th }}$ International Forgemasters Meeting Terni /Spoleto, Italy, 1991.

[2] J. Huez and J-F. Uginet, "Simulation of microstructure of nickel base alloy 706 in production of power generation turbine discs ", $9^{\text {th }}$ International Symposium on Superalloys, Seven Springs, USA, 2000.

[3] C.Plisson, " Mise en forme du superalliage base nickel 706 ", (Internal Report 1997).

[4] Forge $2 \otimes$, a modelling software for the shaping of axisymmetrical and /or two-dimensional parts, Transvalor, BP037, 06901 Sophia Antipolis Cedex - France. 